\title{
Suicide rate lower among boys in lqaluit
}

$\mathrm{I}$ $\mathrm{n}$ a rare positive development concerning suicide among Inuit youth in Canada, new research indicates the rate of suicide among teenage boys is substantially lower in Iqaluit compared to communities outside Nunavut's capital.

Inuit boys aged 15-19 have a suicide rate of 252 per 100000 , about a third of the rate (897 per 100000$)$ among Inuit boys in the same age range living elsewhere in Nunavut, researcher Jack Hicks told the conference on Gender Equality in the Arctic in Akureyri, Iceland, on Oct. 31.

Overall, the rate of suicide among 15- to 19-year-old Inuit boys in Iqaluit is still 20 times the national average; in Nunavut's smaller communities, it is 40 times the national average. According to the latest 2011 Canadian data, the suicide rate for this age group and sex outside Nunavut is 12.5 per 100000 .
Since Nunavut was created in 1999 , 350 males and 84 females aged 10 to 63 have killed themselves in the territory. At least 51 of those deaths were in children aged 15 or under.

Hicks, who is completing a doctorate on suicide among Inuit youth, analyzed the raw data from the Office of the Chief Coroner in Nunavut by sex, age and community of affiliation. There were too few suicides by young women to break them down accurately, he noted.

"There's still a lot of suicidal ideation and suicide attempts among teens in Iqaluit, but the situation is better than in the smaller communities," Hicks, an instructor at Carleton University in Ottawa, told CMAJ.

Historical trauma passed down through generations is a critical risk factor in suicide by Inuit youth, as Hicks and colleagues documented in a follow-back study of 120 people who committed suicide in Nunavut from
2003 to 2006. While boys in Iqaluit are also vulnerable to that intergenerational trauma, other factors are clearly protecting them, Hicks told about 150 scholars, government and business officials attending the conference.

Hicks's research is consistent with that of Dr. Peter Bjerregaard, a professor with the Danish National Institute of Public Health, who examined suicide rates among Greenlanders, most of whom are also Inuit. Rates of suicide by youth 15-29 have fallen since the 1980s in Nuuk, the capital, where they are now the lowest in Greenland. The rates have risen drastically in small and more remote East Greenland, Bjerregaard told $C M A J$ in an email.

"My explanation is that [youth] suicides are related to social conditions, including opportunities for education and employment, but also to societal and cultural changes which came first in the capital," he said.

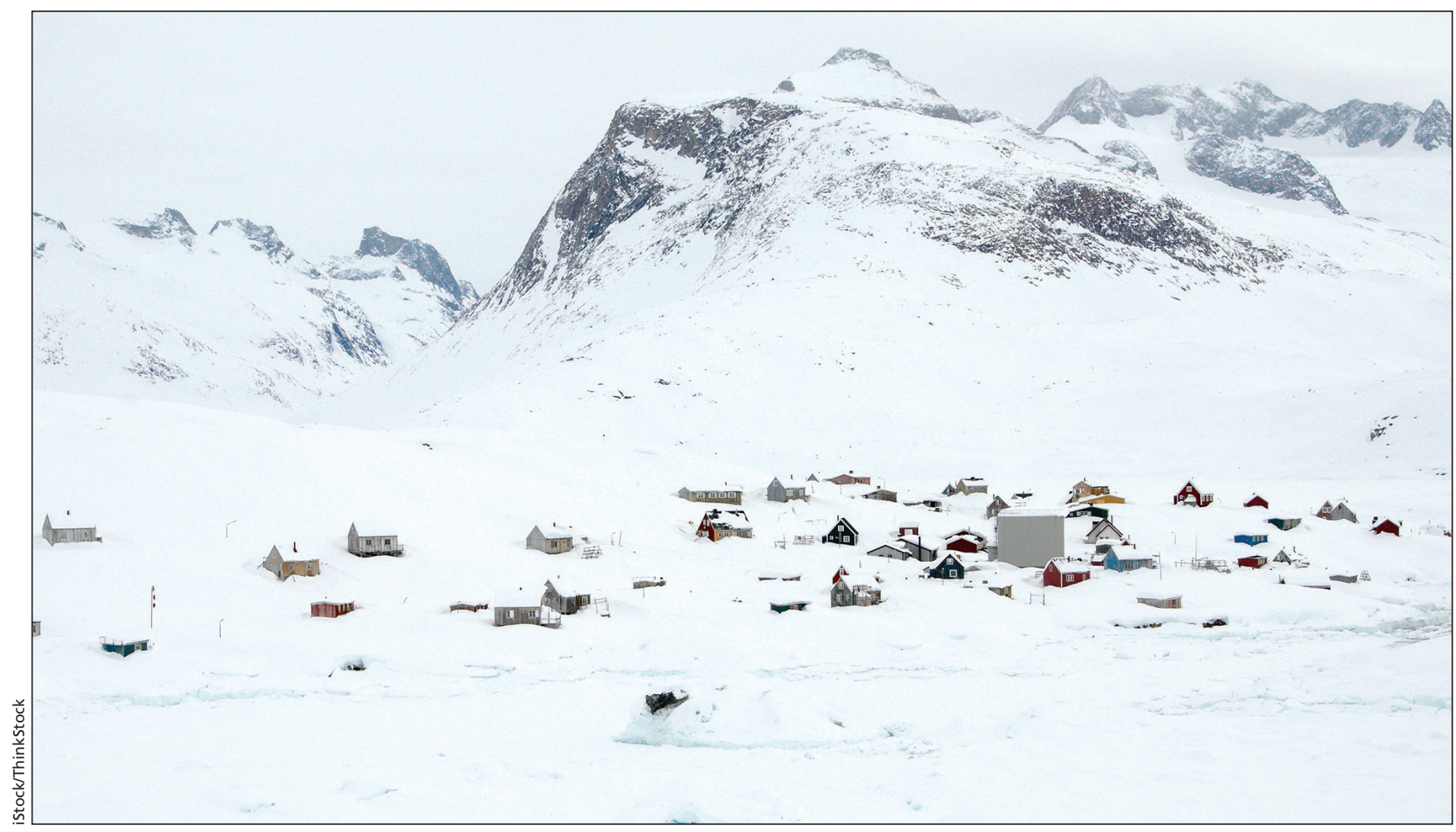

The higher rate of suicide among teenage boys in rural areas may be related to less developed social services and educational opportunities. 
In Alaska, Matthew Berman, a professor of economics at the University of Alaska Anchorage, has also documented a lower rate among indigenous youth in the state's larger cities compared to the smaller communities.

The fact that living in a larger centre protects Inuit boys contradicts a theory held by some researchers who contend that suicide is lower among youth living in communities with greater self-determination, strong language and cultural ties.

"Some people perceive Iqaluit as having a greater degree of cultural loss
- that's the contradiction," says Hicks. "The safest place to be a teenage boy in Inuit societies is in the biggest urban centres."

Although Hicks helped to develop the territory's suicide prevention strategy, he can't yet credit it with having made the startling difference. He says more research is required to explain why the rates are lower, but he believes that stronger daycare, education and mental health services in Iqaluit are among the reasons.

"As weak as they might be in Iqaluit, they are stronger than they are in the smaller communities," Hicks says.
In addition, young boys in Iqaluit may have more positive role models than those in smaller communities. Boys in Iqaluit today are more likely to have fathers and brothers who have completed high school and have jobs. Consequently, the boys see a place for themselves in the wage economy.

"Perhaps it is essentially about boys having more hope for the future in Iqaluit than they do in the smaller communities," says Hicks. — Laura Eggertson, Akureyri, Iceland

CMAJ 2014. DOI:10.1503/cmaj.109-4935 